\title{
Associations between periconceptional lifestyle behaviours and adverse pregnancy outcomes
}

Veronique Y.F. Maas ${ }^{1}$, Marjolein Poels ${ }^{1,2}$, Marije Lamain-de Ruiter ${ }^{3}$, Anneke Kwee ${ }^{4}$, Mireille N. Bekker ${ }^{4}$, Arie Franx ${ }^{1}$ and Maria P.H. Koster ${ }^{1^{*}}$

\begin{abstract}
Background: While the potential adverse outcomes of prenatal exposure to unhealthy lifestyle are widely evidenced, little is known about these exposures in the periconception period. We investigated the associations between lifestyle behaviours and adverse pregnancy outcomes with a unique distinction between preconceptionaland prenatal lifestyle behaviours.

Methods: A secondary analysis took place within a prospective multicentre cohort study in the Netherlands, including 3,684 pregnant women. Baseline characteristics and preconceptional and first trimester lifestyle behaviours were assessed through a self-administered questionnaire in the first trimester. Adverse pregnancy outcomes (hypertensive disorders in pregnancy (HDP), small for gestational age (SGA), gestational diabetes (GDM) and spontaneous preterm birth (SPTB)) were reported by healthcare professionals. Data were collected between 2012 and 2014 and analysed using multivariate logistic regression.

Results: Women who are overweight, and especially obese, have the highest odds of developing any adverse pregnancy outcome (adjusted odds ratio (aOR) 1.61 (95\% Confidence Interval (Cl) 1.31-1.99) and aOR 2.85 (95 \%Cl 2.20-3.68), respectively), particularly HDP and GDM. Women who prenatally continued smoking attained higher odds for SGA (aOR 1.91 (95\% $\%$ 1.05-1.15)) compared to the reference group, but these odds decreased when women prenatally quit smoking (aOR $1.14(95 \% \mathrm{Cl} 0.59-2.21)$ ). Women who did not use folic acid supplements tended to have a higher odds of developing adverse pregnancy outcomes (aOR 1.28 (95\% $\%$ Cl 0.97-1.69)), while women who prenatally started folic acid supplements did not (aOR $1.01(95 \% \mathrm{Cl} 0.82-1.25)$ ).

Conclusions: Our results indicate that smoking cessation, having a normal body mass index (BMI) and initiating folic acid supplements preconceptionally may decrease the risk of adverse pregnancy outcomes. Therefore, intervening as early as the preconception period could benefit the health of future generations.
\end{abstract}

Keywords: Periconception period, Lifestyle behaviours, Pregnancy outcome, Risk factors, Preconception care

\footnotetext{
* Correspondence: m.p.h.koster@erasmusmc.nl

'Department of Obstetrics and Gynaecology, Erasmus MC, University Medical

Centre Rotterdam, Doctor Molewaterplein 40, 3015 GD Rotterdam, the Netherlands

Full list of author information is available at the end of the article
}

(c) The Author(s). 2021 Open Access This article is licensed under a Creative Commons Attribution 4.0 International License, which permits use, sharing, adaptation, distribution and reproduction in any medium or format, as long as you give appropriate credit to the original author(s) and the source, provide a link to the Creative Commons licence, and indicate if changes were made. The images or other third party material in this article are included in the article's Creative Commons licence, unless indicated otherwise in a credit line to the material. If material is not included in the article's Creative Commons licence and your intended use is not permitted by statutory regulation or exceeds the permitted use, you will need to obtain permission directly from the copyright holder. To view a copy of this licence, visit http://creativecommons.org/licenses/by/4.0/. The Creative Commons Public Domain Dedication waiver (http://creativecommons.org/publicdomain/zero/1.0/) applies to the data made available in this article, unless otherwise stated in a credit line to the data. 


\section{Background}

Despite major advances in clinical research and medical technology, the prevalence of adverse maternal and neonatal pregnancy outcomes, such as preeclampsia and preterm birth, has only moderately decreased over the recent decades [1]. Adverse pregnancy outcomes are associated with long-term effects on health, for example, hypertensive disorders of pregnancy (HDP) and gestational diabetes (GDM) are independently associated with an increased risk for cardiovascular disease and type II diabetes [2]. Likewise, adverse neonatal outcomes, for example, preterm birth and small for gestations age (SGA), can have long term consequences among surviving infants, such as medical disabilities, impaired cognitive development, learning difficulties and behaviouraland psychological problems [3]. Evidence suggests that lifestyle changes, such as reducing alcohol use and smoking, losing weight, improving fruit and vegetable consumption, can reduce the prevalence of adverse pregnancy outcomes, especially when initiated in early pregnancy or even before conception [4-7].

The periconception period, defined as the 14 weeks before and 10 weeks after conception, is a critical window with a substantial impact on fetal growth and development [8]. Within this period, gametogenesis, organogenesis and placental development occur. These processes are vulnerable to disturbance of epigenetic mechanisms, leading to an altered profile of embryonic gene expression that persists throughout both pregnancy and childhood [9]. Tobacco- and alcohol consumption are two of the most critical teratogens for prenatal development [10, 11]. According to Dutch guidelines, the prevalence of women who continue smoking and alcohol consumption in at least the first trimester of pregnancy remains $7 \%$ and approximately $40 \%$, respectively [12]. Moreover, in many Western countries, up to $50 \%$ of women are overweight or obese when they become pregnant [13]. The maternal metabolic environment of women who are overweight or obese tends to affect placental development and these women are therefore more prone to develop adverse pregnancy outcomes like GDM or pre-eclampsia [14].

Health promotion activities, such as education, advice and a general health assessment, are likely to improve pregnancy outcomes, by early identification of risk factors encouraging behavioural change [15-17]. One way to incorporate health promotion activities in maternity care is through preconception care (PCC). Several studies aimed to implement PCC programs and some successfully led to an improved level of knowledge regarding PCC and subsequent improved periconceptional lifestyle behaviours $[7,18-20]$. The potential effect of healthy periconceptional lifestyle behaviours on reducing multiple adverse pregnancy outcomes together is yet understudied, and it has been studied only in small sample sizes $[7,21]$. Therefore, the objective of our study was to investigate the association between periconceptional lifestyle behaviours and adverse pregnancy outcomes with a unique distinction between preconceptional- and prenatal lifestyle behaviours.

\section{Methods \\ Design}

From December 2012 through January 2014, a prospective multicentre cohort study was conducted in the central region of the Netherlands; the RESPECT (Risk EStimation for PrEgnancy Complications to provide Tailored care) study. The initial aim of the RESPECT study was to perform an external validation and direct comparison of published prognostic models for early prediction of the risk of developing adverse pregnancy outcomes, including predictors applicable in the first trimester of pregnancy [22]. The current analysis is a secondary analysis of the RESPECT study.

\section{Setting}

Participants were recruited in 31 independent midwifery practices (primary care) and six hospitals (secondary/tertiary care). All pregnant women less than 14 weeks of gestation were included at their initial prenatal visit; there were no exclusion criteria for participating in the RESPECT study. A detailed description of the cohort has previously been published $[22,23]$. The RESPECT study has been approved by the Medical Ethics Committee of the University Medical Centre Utrecht (protocol no. $12-432 / C$ ) and written informed consent was obtained from all individual participants.

\section{Sample}

In total, 4,347 pregnant women participants from the RESPECT study were assessed for eligibility, women with miscarriages before 15 weeks of gestation, women who discontinued their pregnancy or were lost to follow-up were not eligible. For this specific analysis, we excluded women with pregnancies complicated by chromosomal anomalies, births before 18 weeks, multiple pregnancies after multiple imputation (see statistical paragraph). Hence, 3,684 participants were included in this specific analysis as visible in Fig. 1.

\section{Measures}

At enrolment in the first trimester of pregnancy, women were asked to fill out a questionnaire specifically designed for this study. This self-reported questionnaire contained items on socio-demographic characteristics, lifestyle behaviours, and medical, family and obstetrical 


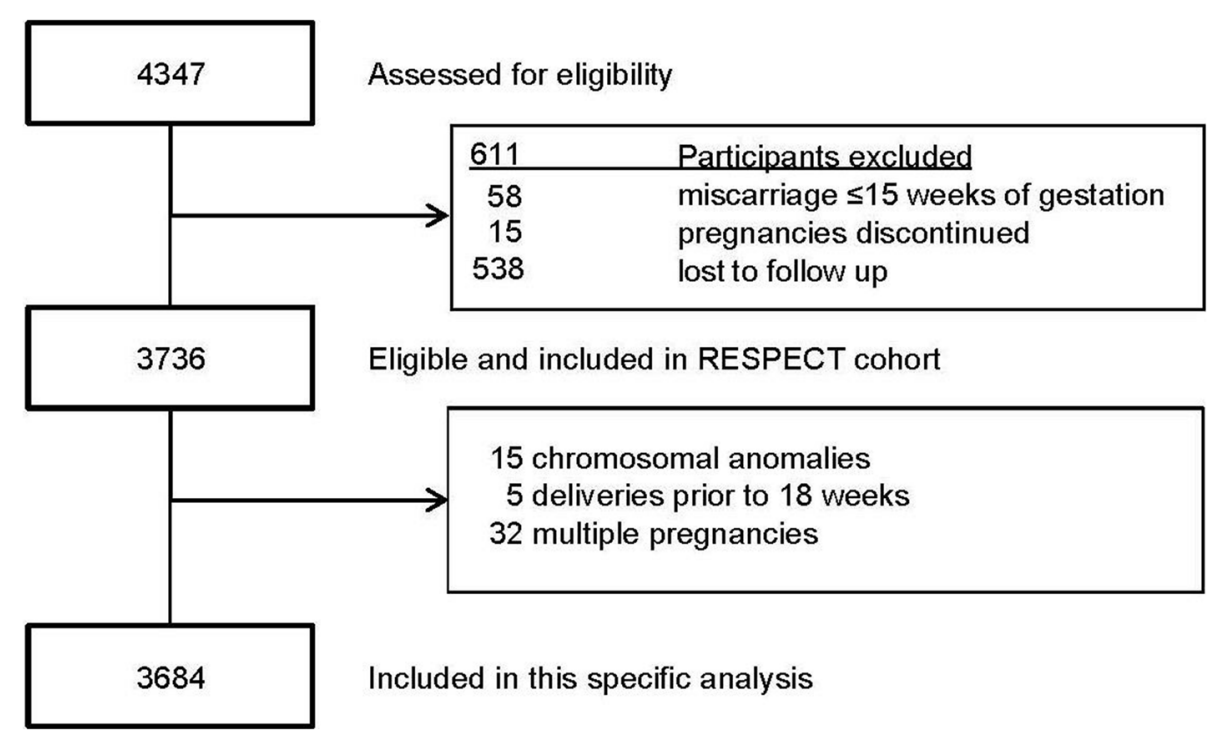

Fig. 1 Flowchart of study participants

history. In the questionnaire, women were asked to recall their lifestyle behaviours in the three-month period before conception and then again for their current lifestyle behaviours (in the first trimester). We were therefore able to measure a difference in lifestyle behaviours for the following lifestyle behaviours: use of tobacco and alcohol and the use of supplements (folic acid, vitamin C, vitamin D, calcium or multivitamin). After birth, healthcare professionals reported the presence or absence of pregnancy outcomes through standardized forms. The definitions of lifestyle behaviours, sociodemographic characteristics and adverse pregnancy outcomes are shown in Table 1 . The use of any vitamin or calcium supplement were combined and analysed as one determinant called 'vitamin use'. As multivitamin includes folic acid, women using multivitamin were categorized in both 'folic acid use' and 'vitamin use'. Body mass index (BMI) was calculated based on self-reported answers to questions concerning one's height and weight before conception. Even though BMI itself is not a lifestyle behaviour, certain lifestyle behaviours such as diet or exercise can influence a person's BMI. The following socio-demographic characteristics were assessed: age, ethnicity, educational level, parity and mode of conception. The following pregnancy outcomes were assessed: hypertensive disorder in pregnancy (HDP; either pregnancy-induced hypertension or preeclampsia), small for gestational age (SGA) defined as birth weight $<3$ rd percentile, gestational diabetes (GDM), and spontaneous preterm birth (sPTB). Table 1 provides details on how these pregnancy outcomes were defined. The choice for these specific pregnancy- and neonatal outcomes was based on its prevalence, the relevance for both mother and child and its need for preventive intervention early in pregnancy. Participants were classified into either having experienced an uncomplicated pregnancy or being diagnosed with any adverse pregnancy outcome, included in our composite outcome. In case of more than one adverse pregnancy outcome, women were assigned to multiple groups. However, since SGA is a common consequence of HDP and these adverse outcomes are therefore likely to co-exist with each other, women with both these outcomes were only assigned to the HDP group. Women were assigned to the SGA group when SGA was the only adverse outcome.

\section{Statistical analysis}

The original dataset contained missing data for some participants; there were 1,111 cases $(30.2 \%)$ with at least one missing value. A more detailed description and an assessment of these missing values can be found in the Appendix (Additional File 1). Missing values were imputed using multiple imputation [22, 33]. All variables and outcomes were used in the imputation model and ten imputations were performed. The results shown are the results after multiple imputation. Rubin's rules were applied to combine the results into summary estimates [34]. Baseline data for all participants are presented as medians and interquartile range (IQR) for continuous variables or as numbers and percentages for categorical variables. Logistic regression analysis was performed to identify associations between lifestyle behaviours and adverse pregnancy outcomes. Crude odds ratios (OR) and accompanying $95 \%$ confidence intervals $(\mathrm{CI})$ were calculated by univariate analysis. Subsequently, adjusted ORs 
Table 1 Overview of demographics and pregnancy outcomes with their definitions

\begin{tabular}{|c|c|c|}
\hline & Variable & Definition \\
\hline \multirow{12}{*}{$\begin{array}{l}\text { Lifestyle Behaviours } \\
\text { (Self-reported in the first } \\
\text { trimester) }\end{array}$} & Body mass index & $\mathrm{Kg} / \mathrm{m}^{2}$ \\
\hline & Underweight & $<18.5 \mathrm{~kg} / \mathrm{m}^{2}$ \\
\hline & Normal weight & $18.5-25 \mathrm{~kg} / \mathrm{m}^{2}$ \\
\hline & Overweight & $25-30 \mathrm{~kg} / \mathrm{m}^{2}$ \\
\hline & Obese & $>30 \mathrm{~kg} / \mathrm{m}^{2}$ \\
\hline & Daily fruit intake & Pieces of fruit \\
\hline & Not-adequate & $<2$ pieces \\
\hline & Adequate & $\geq 2$ pieces \\
\hline & Tobacco use & $\geq 1$ cigarette per day (yes/no) \\
\hline & Alcohol use & $\geq 1$ glass of alcohol per week (yes/no) \\
\hline & Folic acid use & $\begin{array}{l}\text { Use of folic acid, either as a single supplement or as part of multivitamin preparation } \\
\text { (yes/no) }\end{array}$ \\
\hline & Vitamin use & $\begin{array}{l}\text { Use of vitamin C, vitamin D or calcium supplement either as a single supplement or as } \\
\text { part of multivitamin preparation (yes/no) }\end{array}$ \\
\hline \multirow{10}{*}{$\begin{array}{l}\text { Socio-demographic } \\
\text { characteristics } \\
\text { (Self-reported in the first } \\
\text { trimester) }\end{array}$} & Age & Years \\
\hline & Ethnicity & - White: Caucasian or other Western; \\
\hline & & $\begin{array}{l}\text { - Non-White: African, Hindustani, Moroccan, Turkish, Middle Eastern, Asian, other non- } \\
\text { western, and mixed. }\end{array}$ \\
\hline & Educational level & - Low: primary education or lower level; \\
\hline & & - Medium: secondary education; \\
\hline & & - High: tertiary education or higher level. \\
\hline & Parity & - Nulliparous: women with no previous pregnancies beyond 16 weeks; \\
\hline & & - Multiparous: women with previous pregnancies beyond 16 weeks. \\
\hline & Mode of conception & - Spontaneous conception: pregnant without medical assistance; \\
\hline & & $\begin{array}{l}\text { - Non-spontaneous conception: pregnant with ovulation drugs, insemination or in vitro } \\
\text { fertilization/intracytoplasmic sperm injection (IVF/ICSI). }\end{array}$ \\
\hline \multirow{7}{*}{$\begin{array}{l}\text { Adverse pregnancy outcomes } \\
\text { (Reported by the healthcare } \\
\text { provider after the pregnancy) }\end{array}$} & Hypertensive disorder in & Either: \\
\hline & & $\begin{array}{l}\text { - Pregnancy-induced hypertension (PIH): the new onset of hypertension ( } \geq 140 \mathrm{mmHg} \\
\text { systolic and/or } \geq 90 \mathrm{mmHg} \text { diastolic blood pressure) after } 20 \text { weeks gestation mea- } \\
\text { sured on at least two occasions four hours apart; }\end{array}$ \\
\hline & & $\begin{array}{l}\text { - Pre-eclampsia (PE): PIH accompanied by proteinuria ( } \geq 300 \mathrm{mg} \text { in } 24 \text { hours), either dur- } \\
\text { ing pregnancy or postpartum }[24,25,26] \text {. }\end{array}$ \\
\hline & $\begin{array}{l}\text { Small for gestation age } \\
\text { (SGA) }\end{array}$ & A birth weight <3rd percentile, based on Hoftiezer percentiles [27, 28]. \\
\hline & $\begin{array}{l}\text { Gestational diabetes } \\
\text { (GDM) }\end{array}$ & $\begin{array}{l}\text { The presence of either a fasting glucose level of } \geq 7.0 \mathrm{mmol} / \mathrm{L}(126 \mathrm{mg} / \mathrm{dl}) \text { or a glucose } \\
\text { level of } \geq 7.8 \mathrm{mmol} / \mathrm{L}(140 \mathrm{mg} / \mathrm{dl}) \text { two hours after a } 75 \text {-grams oral glucose tolerance } \\
\text { test [29-31]. }\end{array}$ \\
\hline & $\begin{array}{l}\text { Spontaneous preterm } \\
\text { birth (sPTB) }\end{array}$ & A delivery with spontaneous onset before 37 weeks of gestation [32]. \\
\hline & Composite outcome & $\begin{array}{l}\text { Women with one of the following complications; pregnancy-induced hypertension, } \\
\text { pre-eclampsia, small for gestational age }<\text { p3, gestational diabetes, spontaneous preterm } \\
\text { birth or fetal death. }\end{array}$ \\
\hline
\end{tabular}

were calculated by multivariate analysis, taking potential confounders into account (maternal age, educational level, ethnicity, parity and mode of conception). Reference categories were chosen for categorical variables based on the desired lifestyle behaviour based on the Dutch guidelines and the recommended daily intake of vitamins $[12,31]$. The statistical analysis of the data was performed in the final months of 2019, using SPSS version 25.0. $P$-values $<0.05$ were considered statistically significant.

\section{Results}

The median age of the participants in our cohort was 30.8 years (IQR 28.0-33.6) and 3,330 (90.4\%) women 
were Caucasian (Table 2). Conception occurred spontaneously in 3,429 (93.1\%) women, 2,131 (57.8\%) women were highly educated and 1,643 (44.6\%) women were nulliparous. The proportion of women who smoked and used alcohol preconceptionally was $20.9 \%(n=771)$ and $60.9 \%(n=2,244)$, respectively. The majority of these women changed their unhealthy lifestyle behaviours in the first trimester, 492 women (63.8\%) quit smoking and 2,216 women (98.7\%) quit drinking alcohol. A total of 2,177 (59.1\%) women started using folic acid supplements preconceptionally, while 1,077 (29.2\%) women started using folic acid supplement after conception took place.

Table 2 also shows the demographic characteristics and lifestyle behaviours of women who experienced an uncomplicated pregnancy $(n=2,972 ; 80.7 \%)$ versus women who experienced an adverse pregnancy outcome: HDP $(n=298 ; 8.1 \%)$, SGA $(n=133 ; 3.6 \%)$, GDM $(n=$ $184 ; 5.0 \%)$, sPTB $(n=127 ; 3.4 \%)$. In total $712(19.3 \%)$ of all women experienced an adverse pregnancy outcome. These adverse pregnancy outcomes appeared significantly more often when women were non-Caucasian, were low- or medium educated, were nulliparous, had a non-spontaneous conception, were either under-or overweight or smoked preconceptionally.

Table 3 shows the associations between lifestyle behaviours and all adverse pregnancy outcomes. Overall, women who are overweight or obese and women who smoked preconceptionally had higher odds of developing adverse pregnancy outcomes with an adjusted OR of 1.61 (95\%CI 1.13-1.99), 2.85 (95\%CI 2.20-3.68) and 1.32 (95 \%CI 1.03-1.71), respectively. Women with obesity had the highest odds of developing GDM (aOR 6.85 (95\%CI 4.39-10.71)), these increased odds remain in women who are overweight, although much lower (aOR 2.38 (95 \%CI 1.60-3.54)). Women who are overweight or obese were also more likely to develop HDP (aOR 2.17 (95 \%CI 1.63-2.89) and 3.80 (95 \%CI 2.685.40), respectively). In contrast, women with a prepregnancy BMI of $\leq 18.5 \mathrm{~kg} / \mathrm{m}^{2}$ had a higher odds of SGA (aOR 2.64 (95 \%CI 1.17-5.96). We found that women who smoked before pregnancy were more likely to experience sPTB (aOR 1.76 (95\%CI 1.05-2.93)) compared to women who did not smoke preconceptionally. Women who continued to smoke during pregnancy were also more likely to give birth to an SGA neonate aOR 1.91 (95\%CI 1.05-1.15), which was not the case for women who quit smoking after conception (aOR 1.14 (95 \% CI 0.59-2.21)). Women who consumed alcohol preconceptionally, yet discontinued in the first trimester, had a lower odds of developing GDM compared to women who were not used to drink alcohol before pregnancy recognition (aOR 0.65 (95\% CI $0.46-0.93)$ ).
Compared to women who used folic acid supplements from the preconception period onwards, women who did not use folic acid supplements tended to have a (non-significantly) higher odds of developing adverse pregnancy outcomes (aOR 1.28 (95 \%CI 0.97-1.69)), while women who started folic acid supplements during pregnancy did not (aOR 1.01 (95\%CI 0.82-1.25)). No associations were found between daily fruit intake or vitamin use and the development of adverse pregnancy outcomes.

\section{Discussion}

This study confirms that unhealthy periconceptional lifestyle behaviours are associated with a higher prevalence of adverse pregnancy outcomes showing a unique distinction between preconceptional- and prenatal lifestyle behaviours. Women who were obese before pregnancy had the highest odds of developing adverse pregnancy outcomes, particularly HDP and GDM. These odds were much lower in women who are overweight. Women who are underweight, on the other hand, were more likely to give birth to an SGA neonate. Smoking before the pregnancy was associated with SPTB and SGA, but, interestingly, for SGA this association did not persist when women quit smoking during the first trimester. Therefore, encouraging women to quit smoking in the first trimester could reduce the odds for SGA to those of a non-smoker.

We found that women with a BMI of $25 \mathrm{~kg} / \mathrm{m}^{2}$ or more, especially women with a BMI above $30 \mathrm{~kg} / \mathrm{m}^{2}$, have the highest odds of developing adverse pregnancy outcomes. Improving one's exercising pattern through health-promoting interventions could benefit these women as previous meta-analyses suggest that higher amounts of preconception physical activity are associated with a lower risk of GDM and pre-eclampsia [35, 36]. In addition, a population-based study showed that a $10 \%$ lower preconception BMI was associated with clinically meaningful risk reduction in pre-eclampsia, GDM, preterm birth, macrosomia, and stillbirth [4]. A previous study showed that only $57 \%$ of pregnant women were aware of the fact that obesity increases the overall risk of pregnancy- and birth complications and that weight loss before the pregnancy can reduce to overall risk for complications [37]. Hence, here lies an opportunity for PCC to encourage women with obesity to enter weight loss programs to improve their own health and the health of their future child.

In accordance with previous studies, we indeed found that smoking is associated with a higher odds of sPTB and birth of SGA neonates [38-41]. Although some studies showed that pregnant women who quit smoking during the first trimester are no longer at risk for sPTB, 
Table 2 Demographics and lifestyle behaviours of study participants stratified by pregnancy outcome

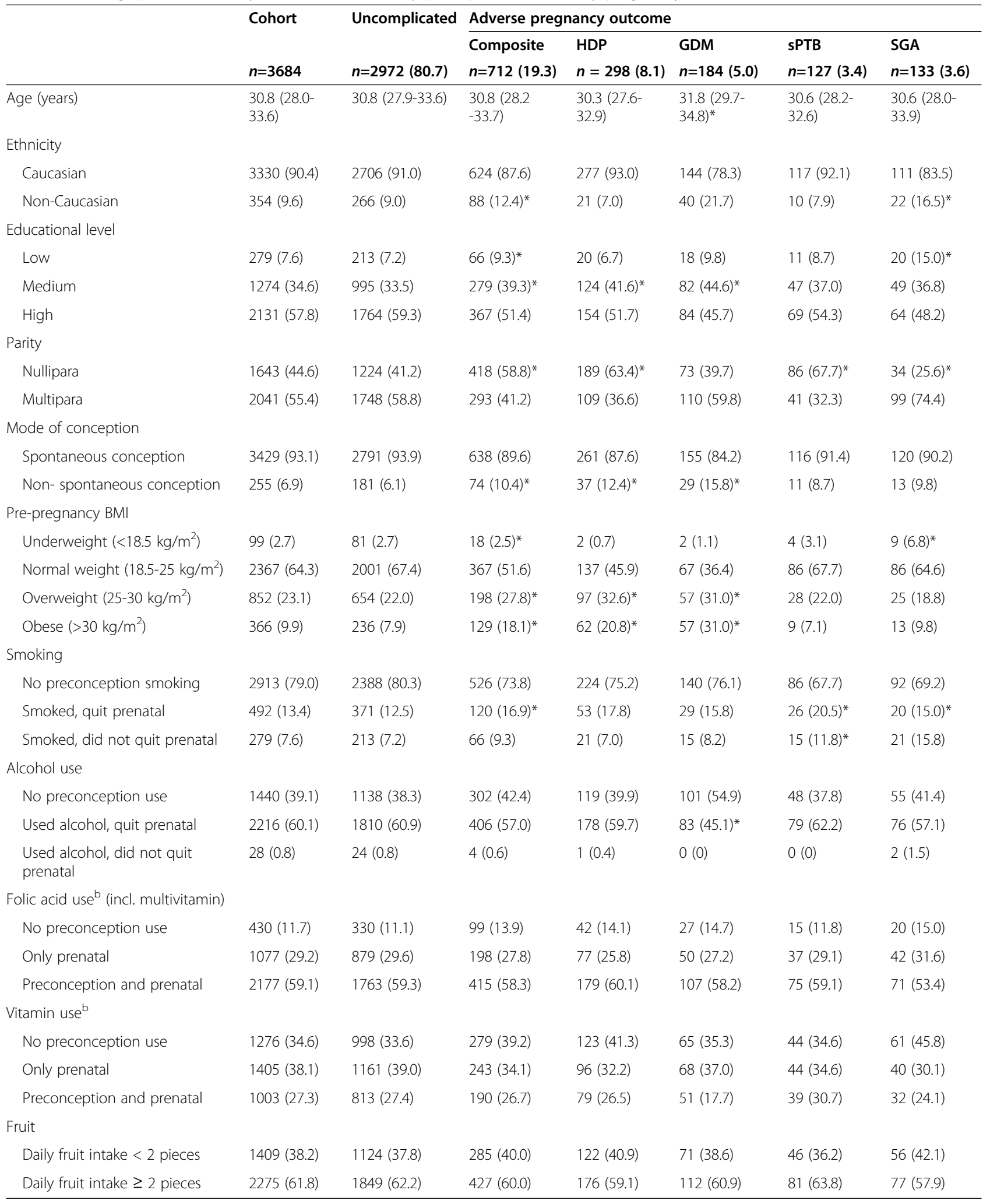

values are presented as median (IQR) or $\mathrm{n}(\%)$

participants can have more than 1 adverse pregnancy outcome therefore the numbers do not add up

HDP hypertensive disorders in pregnancy, GDM gestational diabetes, sPTB spontaneous preterm birth, SGA small for gestational age

*differs significantly from the uncomplicated group based on logistic regression analysis, $p<0.05$

a composite outcome: women with one of the following complications; HDP, SGA, GDM, sPTB or fetal death

bwomen using multivitamin were categorized in both 'folic acid use' and 'vitamin use' 


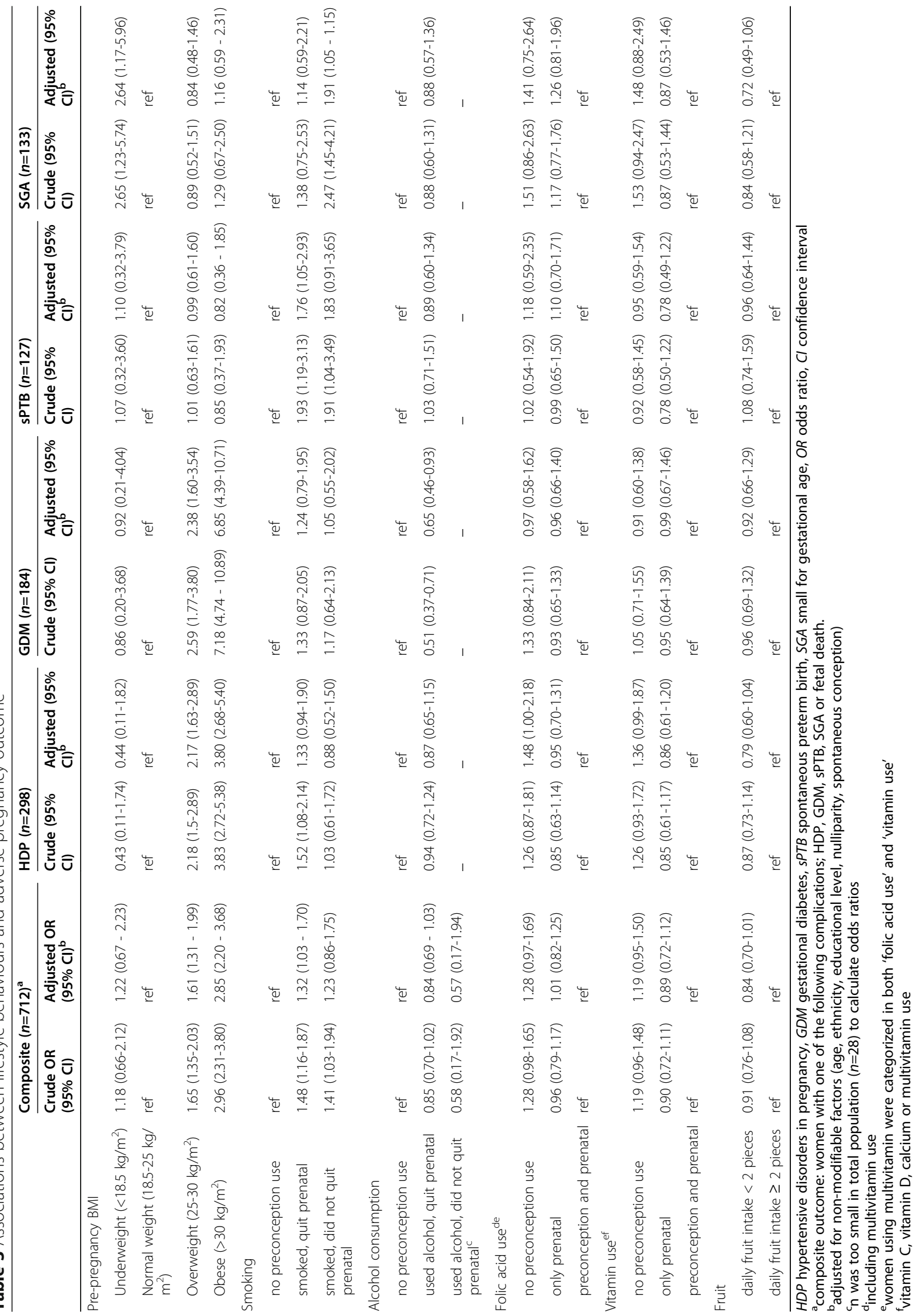


our results show that women who quit smoking and women who continue to smoke (although not significant) both have increased odds for sPTB [42-44]. On the other hand, we found that women who quit smoking in the first trimester did have similar odds of developing SGA compared to non-smokers, as previous studies have also suggested [40, 41, 43]. Cigarette smoke contains substances that affect placental endothelial function, which can lead to the development of ischemic vascular changes impacting placental growth and functions [45]. A previous systematic review showed that cessation of smoking before and shortly after becoming pregnant was not associated with SGA and this suggests that the mechanisms affecting fetal growth predominantly act beyond the first trimester [46]. Nevertheless, smoking cessation before conception remains the best approach to improve health benefits.

Alcohol is suggested to lower levels of inflammation markers and endothelial dysfunction, increase insulin sensitivity, increase HDL cholesterol concentrations, which, for example, may lower the risk of type 2 diabetes mellitus and possibly also GDM [47-49]. Several previous studies indicated that (heavy) alcohol consumption during pregnancy increases the risk of low birth weight and preterm birth, while light alcohol consumption may possibly have a mildly protective effect on these outcomes [50, 51]. The possible explanation provided for this paradox is the "healthy drinker effect", in which women with poor obstetric prognosis, socio-economic status or well-being are more likely to abstain from drinking alcohol $[50,51]$. While we were not able to measure the amount of alcohol consumed, we indeed found that women who used alcohol preconceptionally were significantly more often Caucasian, higher educated, nulliparous, were pregnant by spontaneous conception, had a lower pre-pregnancy BMI and used more folic acid supplements compared to women who did not use alcohol preconceptionally (data not shown).

Finally, our results showed that encouraging women to start folic acid supplements, after pregnancy recognition, can still benefit the health of mother and child. Although non-significant, we found a higher odds of adverse pregnancy outcomes for women who did not use folic acid supplements compared to preconceptional commencement. Although we found no difference in adverse pregnancy outcomes between women who started folic acid supplements before or during the pregnancy, it is widely evidenced that early initiation (ideally before conception) of folic acid supplements does decrease the risk for congenital malformations such as neural tube defects [52]. In our study, congenital malformations were excluded from analysis and therefore we cannot provide any results regarding these outcomes.
Our results are relevant since an unhealthy diet, lifestyle behaviours and exercising pattern are progressively becoming part of Western society, including among a high percentage of women in their reproductive age [5, $6,16]$. Encouraging women to develop and maintain a healthy lifestyle has long been a focus of prenatal care, while our findings support emerging evidence indicating that the preconception period might even be a better window of opportunity to address these unhealthy lifestyle behaviours. PCC is known to increase the health and well-being of prospective parents, still, the uptake of PCC-consults remains remarkably low [53]. This is particularly the case for vulnerable women, who often have multiple unhealthy lifestyle behaviours and are specifically hard to reach [54]. PCC interventions often require engagement from prospective parents who are not yet thinking about becoming a parent in the future and are not yet known by maternal health services [55]. Although some studies suggest that awareness of preconception health and care is low, pregnancy planning appears relatively common, indicating a missed and unexploited opportunity for intervention [56-58].

A possible strength of this study is that we used a large, multicentre, population-based cohort where we accounted for missing data by using multiple imputation, which decreases the risk of selection bias and allows to investigate multiple exposures and outcomes. Also, we distinguished lifestyle behaviours between the preconception period and the first trimester, a distinction rarely made in previous studies. A limitation of this study is the underrepresentation of non-caucasian and lower educated women. Future studies should focus on analysing these associations in a more heterogeneous study population. In addition, the data on lifestyle behaviours is collected by the use of self-administered questionnaires. Although this method is suggested to negatively affect the validity, we merely assessed the presence (yes/no questions) instead of frequencies of lifestyle behaviours, by which we probably have diminished the chance of over-or underreporting of behaviour [59]. However, to be able to make the distinction between preconception and first trimester exposure to unhealthy lifestyle behaviours depends upon women's perception of when conception exactly occurred. Moreover, examining potential dose-response relationships was not possible and blood markers were not available to validate, for example, micronutrient or smoking status. Finally, as this study was only able to measure associations between periconceptional lifestyle behaviours and adverse pregnancy outcomes, and the sample size calculation was not performed for the current aim of this paper, results should be interpreted with caution and we recommend future research to focus on largescale interventions to discover a possible (causal) effect. 


\section{Conclusions}

Overall, our findings indicate that women should be encouraged to change unhealthy lifestyle behaviours, preferably before conception. Therefore, future research on interventions to improve awareness of the importance of PCC and the (cost)effectiveness of these interventions on pregnancy outcomes are needed. Findings from such studies could enhance the choice to start future preventive measures and interventions regarding unhealthy periconceptional lifestyle behaviours, to optimize the health of future generations.

\section{Abbreviations}

aOR: Adjusted odds ratio; BMI: Body mass index; Cl: Confidence interval; GDM: Gestational diabetes; HDP: Hypertensive disorders in pregnancy; IQR: Interquartile range; PCC: Preconception care; PE: Pre-eclampsia; PIH: Pregnancy-induced hypertension; RESPECT study: Risk EStimation for PrEgnancy Complications to provide Tailored care; SGA: Small for gestational age; sPTB: Spontaneous preterm birth

\section{Supplementary Information}

The online version contains supplementary material available at https://doi. org/10.1186/s12884-021-03935-x.

Additional file 1. Baseline characteristics stratified by variables that were available for imputation

\section{Acknowledgements}

We would like to thank all pregnant women who participated in the RESP ECT study. We would like to thank the late dr. Henk van der Stel (Julius Centre for Health Sciences and Primary Care, University Medical Center Utrecht) for his contribution. We would like to thank the collaborators in the RESPECT study group: I. de Groot; I.M. Evers; F. Groenendaal; Y. Hering; A.J.M. Huisjes; C. Kirpestein; W.M. Monincx; J.E. Siljee; A. van 't Zelfde; C.M. van Oirschot; S. Vankan-Buitelaar; M.A.A.W. Vonk; T.A. Wiegers and J.J. Zwart.

\section{Authors' contributions}

MPHK, AK, AF and the RESPECT study group were involved in writing the original RESPECT study protocol. The RESPECT study group and MLdR were involved in data collection. WYF, MP and MLdR performed the data analysis. VYF, MP and MPHK wrote the first draft of the manuscript, which was subsequently revised by MLdR, AK, MNB and AF. MPHK and AF are the guarantors of this study. All authors participated in the final approval of the manuscript.

\section{Funding}

This study has been conducted with the support of The Netherlands Organization for Health Research and Development (ZonMw), grant no. 209020004 and grant no. 209040005.

\section{Availability of data and materials}

The dataset for the current study is available from the corresponding author upon reasonable request.

\section{Declarations}

\section{Ethics approval and consent to participate}

The RESPECT study has been approved by the Medical Ethics Committee of the University Medical Centre Utrecht (protocol no. 12-432/C) and written informed consent was obtained from all individual participants. All methods were performed in accordance with the relevant guidelines and regulations confirm the Declaration of Helsinki.

\section{Consent for publication}

Not applicable.

\section{Competing interests}

The authors declare that they have no competing interests.

\section{Author details}

${ }^{1}$ Department of Obstetrics and Gynaecology, Erasmus MC, University Medical Centre Rotterdam, Doctor Molewaterplein 40, 3015 GD Rotterdam, the Netherlands. ${ }^{2}$ Research Agency Care2Research, Mattenbiesstraat 133, $1087 \mathrm{GC}$ Amsterdam, the Netherlands. ${ }^{3}$ Research Agency Frontida Analytics, Prinses Irenelaan 95, 3554HD Utrecht, the Netherlands. ${ }^{4}$ Department of Obstetrics and Gynaecology, Division Woman and Baby, University Medical Centre Utrecht, Lundlaan 6, 3584 EA Utrecht, the Netherlands.

Received: 27 January 2021 Accepted: 31 May 2021

Published online: 07 July 2021

\section{References}

1. Atrash HK, Johnson K, Adams M, Cordero JF, Howse J. Preconception care for improving perinatal outcomes: the time to act. Matern Child Health J. 2006;10(5 Suppl):S3-11.

2. Fraser A, Nelson SM, Macdonald-Wallis C, Cherry L, Butler E, Sattar N, et al. Associations of pregnancy complications with calculated cardiovascular disease risk and cardiovascular risk factors in middle age: the Avon Longitudinal Study of Parents and Children. Circulation. 2012;125(11):136780.

3. Moster D, Lie RT, Markestad T. Long-term medical and social consequences of preterm birth. N Engl J Med. 2008;359(3):262-73.

4. Schummers L, Hutcheon JA, Bodnar LM, Lieberman E, Himes KP. Risk of adverse pregnancy outcomes by prepregnancy body mass index: a population-based study to inform prepregnancy weight loss counseling. Obstet Gynecol. 2015;125(1):133-43.

5. Lassi ZS, Imam AM, Dean SV, Bhutta ZA. Preconception care: caffeine, smoking, alcohol, drugs and other environmental chemical/radiation exposure. Reprod Health. 2014;11 Suppl 3:S6.

6. Dean SV, Lassi ZS, Imam AM, Bhutta ZA. Preconception care: nutritional risks and interventions. Reprod Health. 2014;11 Suppl 3:S3.

7. Elsinga J, de Jong-Potjer LC, van der Pal-de Bruin KM, le Cessie S, Assendelft WJ, Buitendijk SE. The effect of preconception counselling on lifestyle and other behaviour before and during pregnancy. Womens Health Issues. 2008; 18(6 Suppl):S117-25.

8. Steegers-Theunissen RP, Twigt J, Pestinger V, Sinclair KD. The periconceptional period, reproduction and long-term health of offspring: the importance of one-carbon metabolism. Hum Reprod Update. 2013; 19(6):640-55.

9. Fleming TP, Watkins AJ, Velazquez MA, Mathers JC, Prentice AM, Stephenson J, et al. Origins of lifetime health around the time of conception: causes and consequences. Lancet. 2018;391(10132):1842-52.

10. Murphy DJ, Mullally A, Cleary BJ, Fahey T, Barry J. Behavioural change in relation to alcohol exposure in early pregnancy and impact on perinatal outcomes-a prospective cohort study. BMC Pregnancy Childbirth. 2013;13:8.

11. Kawashima A, Koide K, Ventura W, Hori K, Takenaka S, Maruyama D, et al. Effects of maternal smoking on the placental expression of genes related to angiogenesis and apoptosis during the first trimester. PloS one. 2014;9(8): e106140 e.

12. College Perinatale Zorg (Perinatal Care College). Preconceptie Indicatie Lijst (preconception indication list). 2018. https://www.kennisnetgeboortezorg.nl/ wp-content/uploads/2019/06/Preconceptie_Indicatie_Lijst_PIL_.pdf. Accessed 10 Dec 2019

13. Stephenson J, Heslehurst N, Hall J, Schoenaker DAJM, Hutchinson J, Cade JE, et al. Before the beginning: nutrition and lifestyle in the preconception period and its importance for future health. Lancet. 2018;391(10132):1830-41.

14. Catalano PM, Shankar K. Obesity and pregnancy: mechanisms of short term and long term adverse consequences for mother and child. BMJ. 2017;356:j1.

15. Whitworth M, Dowswell T. Routine pre-pregnancy health promotion for improving pregnancy outcomes. Cochrane Database Syst Rev. 2009;4(4): CD007536. https://doi.org/10.1002/14651858.CD007536.pub2.

16. Zhao G, Ford ES, Tsai J, Li C, Ahluwalia IB, Pearson WS, et al. Trends in health-related behavioral risk factors among pregnant women in the United States: 2001-2009. J Womens Health (Larchmt). 2012;21(3):255-63.

17. Hoover EA, Louis JM. Optimizing Health: Weight, Exercise, and Nutrition in Pregnancy and Beyond. Obstet Gynecol Clin North Am. 2019;46(3):431-40. 
18. Poels M, van Stel HF, Franx A, Koster MPH. The effect of a local promotional campaign on preconceptional lifestyle changes and the use of preconception care. Eur J Contracept Reprod Health Care. 2018;23(1):38-44.

19. Sijpkens MK, van Voorst SF, de Jong-Potjer LC, Denktaş S, Verhoeff AP, Bertens LCM, et al. The effect of a preconception care outreach strategy: the Healthy Pregnancy 4 All study. BMC Health Serv Res. 2019;19(1):60.

20. van der Windt M, van der Kleij RM, Snoek KM, Willemsen SP, Dykgraaf RHM, Laven JSE, et al. Impact of a blended periconception lifestyle care approach on lifestyle behaviors: Before-and-after study. J Med Internet Res. 2020;22(9): e19378.

21. Jourabchi Z, Sharif S, Lye MS, Saeed A, Khor GL, Tajuddin SHS. Association Between Preconception Care and Birth Outcomes. Am J Health Prom. 2019; 33(3):363-71.

22. Lamain-de Ruiter M, Kwee A, Naaktgeboren CA, de Groot I, Evers IM, Groenendaal F, et al. External validation of prognostic models to predict risk of gestational diabetes mellitus in one Dutch cohort: prospective multicentre cohort study. BMJ. 2016:354:i4338.

23. Lamain-de Ruiter M, Kwee A, Naaktgeboren CA, Louhanepessy RD, De Groot I, Evers IM, et al. External validation of prognostic models for preeclampsia in a Dutch multicenter prospective cohort. Hypertens Pregnancy. 2019;38(2):78-88.

24. NVOG: Dutch Society of Obstetrics and Gynecology. Chronische Hypertensie in de zwangerschap (Chronic hypertension in pregnancy) - Guideline. 2011. https://www.nvog.nl/wp-content/uploads/2017/12/Chronische-hypertensiein-de-zwangerschap-2.0-16-03-2005.pdf. Accessed 10 Jan 2020.

25. Brown MA, Lindheimer MD, de Swiet M, Assche AV, Moutquin J-M. The classification and diagnosis of the hypertensive disorders of pregnancy: statement from the International Society for the Study of Hypertension in Pregnancy (ISSHP). Taylor \& Francis; 2001.

26. Tranquilli AL, Brown MA, Zeeman GG, Dekker G, Sibai BM. The definition of severe and early-onset preeclampsia. Statements from the International Society for the Study of Hypertension in Pregnancy (ISSHP). Pregnancy Hypertens: Int J Women's Cardiovasc Health. 2013;3(1):44-7.

27. Visser GH, Eilers PH, Elferink-Stinkens PM, Merkus HM, Wit JM. New Dutch reference curves for birthweight by gestational age. Early Hum Dev. 2009; 85(12):737-44.

28. Hoftiezer L, Hof MHP, Dijs-Elsinga J, Hogeveen M, Hukkelhoven C, van Lingen RA. From population reference to national standard: new and improved birthweight charts. Am J Obstet Gynecol. 2019;220(4):383.e1-.e17.

29. Alberti KG, Zimmet PZ. Definition, diagnosis and classification of diabetes mellitus and its complications. Part 1: diagnosis and classification of diabetesmellitus provisional report of a WHO consultation. Diabet Med. 1998;15(7):539-53.

30. NDF: Dutch Diabetes Federation. Zorgstandaard Diabetes (Diabetes Guideline)- Guideline. 2015. http://www.zorgstandaarddiabetes.nl/ wpcontent/uploads/2015/08/NDF-Zorgstandaard-diabetes-type-2-Volwa ssenen-2015.pdf. Accessed 20 Jan 2020.

31. Gezondheidsraad (Dutch Health Council). Voedingsnormen calcium, vitamine D,thiamine, riboflavine, niacine, pantotheenzuur en biotine (Dietary reference values calcium, vitamin $\mathrm{D}$, thiamine, riboflavin, niacin, pantothenic acid and biotin). 2000. Den Haag. https://www.gezondheidsraad.nl/documenten/a dviezen/2000/07/13/voedingsnormen-calcium-vitamine-d-thiamine-riboflavineniacine-pantotheenzuur-en-biotine. Accessed 10 Dec 2019.

32. Lumley J. Defining the problem: the epidemiology of preterm birth. BJOG: Int J Obstet Gynaecol. 2003;110:3-7.

33. Sterne JA, White IR, Carlin JB, Spratt M, Royston P, Kenward MG, et al. Multiple imputation for missing data in epidemiological and clinical research: potential and pitfalls. BMJ. 2009;338:b2393.

34. Rubin D. Multiple imputation for nonresponse in surveys. Wiley Online Library; 1987.

35. Tobias DK, Zhang C, van Dam RM, Bowers K, Hu FB. Physical activity before and during pregnancy and risk of gestational diabetes mellitus: a metaanalysis. Diabetes Care. 2011;34(1):223-9.

36. Aune D, Saugstad OD, Henriksen T, Tonstad S. Physical activity and the risk of preeclampsia: a systematic review and meta-analysis. Epidemiology (Cambridge, Mass). 2014;25(3):331-43.

37. Nitert MD, Foxcroft KF, Lust K, Fagermo N, Lawlor DA, O'Callaghan M, et al. Overweight and obesity knowledge prior to pregnancy: a survey study. BMC Pregnancy Childbirth. 2011;11:96

38. Shah NR, Bracken MB. A systematic review and meta-analysis of prospective studies on the association between maternal cigarette smoking and preterm delivery. Am J Obstet Gynecol. 2000;182(2):465-72.
39. McCowan LM RC, Dekker GA, et al. Risk factors for small-for-gestational-age infants by customised birthweight centiles: Data from an international prospective cohort study. BJOG. 2010;117(13):1599-607.

40. Bernstein IM, Mongeon JA, Badger GJ, Solomon L, Heil SH, Higgins ST. Maternal smoking and its association with birth weight. Obstet Gynecol. 2005;106(5 Pt 1):986-91.

41. Reeves S, Bernstein I. Effects of maternal tobacco-smoke exposure on fetal growth and neonatal size. Expert Rev Obstet Gynecol. 2008;3(6):719-30.

42. Moore E, Blatt K, Chen A, Van Hook J, DeFranco EA. Factors Associated with Smoking Cessation in Pregnancy. Am J Perinatol. 2016;33(6):560-8.

43. Polakowski LL, Akinbami LJ, Mendola P. Prenatal smoking cessation and the risk of delivering preterm and small-for-gestational-age newborns. Obstet Gynecol. 2009;114(2 Pt 1):318-25.

44. Jaddoe WW, Troe EJ, Hofman A, Mackenbach JP, Moll HA, Steegers EA, et al. Active and passive maternal smoking during pregnancy and the risks of low birthweight and preterm birth: the Generation R Study. Paediatr Perinat Epidemiol. 2008:22(2):162-71.

45. Aliyu MH, Lynch ON, Wilson RE, Alio AP, Kristensen S, Marty PJ, et al. Association between tobacco use in pregnancy and placenta-associated syndromes: a population-based study. Arch Gynecol Obstet. 2011;283(4): 729-34.

46. Abraham M, Alramadhan S, Iniguez C, Duijts L, Jaddoe WW, Den Dekker HT, et al. A systematic review of maternal smoking during pregnancy and fetal measurements with meta-analysis. PLoS One. 2017;12(2):e0170946.

47. Koppes LL, Dekker JM, Hendriks HF, Bouter LM, Heine RJ. Moderate alcohol consumption lowers the risk of type 2 diabetes: a meta-analysis of prospective observational studies. Diabetes Care. 2005;28(3):719-25.

48. Howard AA, Arnsten JH, Gourevitch MN. Effect of alcohol consumption on diabetes mellitus: a systematic review. Ann Intern Med. 2004;140(3):211-9.

49. Bouthoorn SH, Silva LM, Murray SE, Steegers EA, Jaddoe WW, Moll H, et al. Low-educated women have an increased risk of gestational diabetes mellitus: the Generation R Study. Acta Diabetol. 2015;52(3):445-52.

50. Henderson J, Gray R, Brocklehurst P. Systematic review of effects of lowmoderate prenatal alcohol exposure on pregnancy outcome. BJOG. 2007; 114(3):243-52.

51. Patra J, Bakker R, Irving H, Jaddoe WW, Malini S, Rehm J. Dose-response relationship between alcohol consumption before and during pregnancy and the risks of low birthweight, preterm birth and small for gestational age (SGA)-a systematic review and meta-analyses. BJOG. 2011;118(12):1411-21.

52. De-Regil LM, Fernandez-Gaxiola AC, Dowswell T, Pena-Rosas JP. Effects and safety of periconceptional folate supplementation for preventing birth defects. Cochrane Database Syst Rev. 2010;10(10):CD007950. https://doi. org/10.1002/14651858.CD007950.pub2.

53. World Health O. Meeting to develop a global consensus on preconception care to reduce maternal and childhood mortality and morbidity: World Health Organization Headquarters, Geneva, 6-7 February 2012: Meeting report. 2013.

54. M'Hamdi H I, van Voorst SF, Pinxten W, Hilhorst MT, Steegers EA. Barriers in the Uptake and Delivery of Preconception Care: Exploring the Views of Care Providers. Matern Child Health J. 2017;21(1):21-8.

55. Barker M, Dombrowski SU, Colbourn T, Fall CHD, Kriznik NM, Lawrence WT, et al. Intervention strategies to improve nutrition and health behaviours before conception. Lancet. 2018;391(10132):1853-64.

56. Stephenson J, Patel D, Barrett G, Howden B, Copas A, Ojukwu O, et al. How do women prepare for pregnancy? Preconception experiences of women attending antenatal services and views of health professionals. PloS One. 2014;9(7):e103085-e.

57. Bitzer J, von Stenglin A, Bannemerschult R. Women's awareness and periconceptional use of folic acid: data from a large European survey. Int J Womens Health. 2013;5:201-13.

58. Inskip HM, Crozier SR, Godfrey KM, Borland SE, Cooper C, Robinson SM. Women's compliance with nutrition and lifestyle recommendations before pregnancy: general population cohort study. BMJ. 2009;338:b481.

59. Gollenberg AL, Mumford SL, Cooney MA, Sundaram R, Louis GM. Validity of retrospectively reported behaviors during the periconception window. J Reprod Med. 2011;56(3-4):130-7.

\section{Publisher's Note}

Springer Nature remains neutral with regard to jurisdictional claims in published maps and institutional affiliations. 